\title{
Saberes e práticas locais dos produtores de guaraná (Paullinia cupana Kunth var. sorbilis) do médio Amazonas: duas organizações locais frente à inovação \\ Local knowledge and practices of guarana producers (Paullinia cupana Kunth var. sorbilis) on the middle Amazon: two grassroots organizations confronting innovation
}

\author{
Solène Tricaud", Florence Pinton", Henrique dos Santos Pereira III \\ I Instituto Centro de Vida. Cuiabá, Mato Grosso, Brasil \\ "AgroParisTech. Paris, França / "'Universidade Federal do Amazonas. Manaus, Amazonas, Brasil
}

\begin{abstract}
Resumo: $\bigcirc$ guaraná (Paullinia cupana Kunth var. sorbilis) é uma planta nativa da Amazônia, conhecida mundialmente por suas propriedades estimulantes. Desde 1974, um processo de modernização dos sistemas de cultivo vem sendo difundido na região por agroindústria monopolista e por empresa de pesquisa agropecuária. Isso se traduziu na difusão de pacotes tecnológicos modernizantes, visando ao aumento da produtividade agrícola. Manejada e consumida originalmente pelos indígenas Sateré-Mawé, o produto vem perdendo vínculo com seu território de origem, o que estimulou, a partir dos anos 1990, a busca por alternativas de valorização da procedência e do modo de produção de base familiar e agroecológica. A pesquisa, realizada com produtores de duas organizações locais do baixo Amazonas, buscou revelar suas inciativas de reterritorialização da produção, suas práticas de manejo e conservação in situ da planta, e suas reações à difusão de formas inovadoras de produção e de inserção no mercado. Partindo-se da hipótese da existência de uma dinâmica funcional diferente em cada organização, identificamos que as relações dos produtores com o mercado, com a proteção do conhecimento tradicional e com a própria planta evoluíram em trajetórias sócio-históricas distintas, as quais resultaram em diferentes sistemas de referências socioculturais, ecológicas e tecnológicas.
\end{abstract}

Palavras-chave: Manejo do guaraná. Amazônia brasileira. Agricultura familiar. Cadeia produtiva. Organização coletiva. Território.

\begin{abstract}
Guarana (Paullinia cupana Kunth var. sorbilis) is a native plant of the Amazon, known worldwide for its stimulant properties. Since 1974, a process of modernization of farming systems has been widespread in the region by monopolistic agribusiness and agricultural research companies. This has resulted in the dissemination of modernizing technological packages aimed at increasing agricultural productivity. Managed and originally consumed by Sateré-Mawé indians, guarana has lost the link with its region of origin, which from 1990 on stimulated the search for alternative valorization of the origin and of family-based and agroecologically-based production. Research, conducted with producers of two local organizations from the lower Amazon aimed to identify initiatives to further re-territorialization of production, management practices and in situ conservation of the plant, as well as reactions to the dissemination of innovative forms of production and marketing. Starting from the hypothesis that different functional dynamics exist in each organization, we established that the producers' relationships with the market, with traditional knowledge protection and with the plant itself evolved in different socio-historical trajectories. These trajectories resulted in different systems of socio-cultural, ecological and technological reference.
\end{abstract}

Keywords: Guarana management. Brazilian Amazon. Family farming. Value chain. Collective organization. Territory.

TRICAUD, Solène; PINTON, Florence; PEREIRA, Henrique dos Santos. Saberes e práticas locais dos produtores de guaraná (Paullinia cupana Kunth var. sorbilis) do médio Amazonas: duas organizações locais frente à inovação. Boletim do Museu Paraense Emílio Goeldi. Ciências Humanas, v. 11, n. 1, p. 33-53, jan.-abr. 2016. DOI: http://dx.doi.org/10.1590/1981.81222016000100004.

Autor para correspondência: Florence Pinton. Agroparistech/SADAPT, 16 rue Claude Bernard, 75231 Paris Cedex 05, France (florence. pinton@agroparistech.fr).

Recebido em 29/01/2013

Aprovado em 23/03/2016

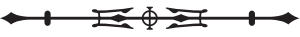




\section{INTRODUÇÃO}

No quadro dos debates internacionais sobre o desenvolvimento sustentável e a conservação da biodiversidade houve uma reconsideração das populações locais e de seus saberes e práticas associados à gestão dos recursos naturais. A Convenção sobre a Diversidade Biológica (1992) traduz essa mudança de paradigma, ressaltando a importância dos Conhecimentos Tradicionais Associados (CTA) dessas populações para a conservação e a renovação da biodiversidade selvagem ou cultivada. Para pôr um fim ao processo de extinção da biodiversidade e dos conhecimentos tradicionais associados, a convenção sugere o desenvolvimento de mercados baseados na sua promoção (Aubertin et al., 2007). Aparecem, então, mecanismos de diversificação da oferta de produtos agrícolas e de desenvolvimento dos territórios, inspirados nos modelos europeus e apoiados pelas políticas de desenvolvimento sustentável (Boisvert e Caron, 2007; Cerdan e Vitrolles, 2008; Cerdan e Sautier, 2003; Niederle, 2013). Trata-se de selos e certificações que valorizam critérios ambientais (agricultura orgânica, gestão sustentável dos ecossistemas), nutricionais, sociais, econômicos (comércio solidário) ou, ainda, especificidades territoriais (indicação geográfica).

Estes movimentos têm lugar em um contexto no qual a participação de cidadãos na definição das políticas públicas é afirmada na Constituição Federal de 1988 e na implementação de instrumentos de territorialização da ação pública que institucionalizaram o debate participativo em todos os territórios. A criação de territórios da cidadania1 em 2008 (Witkoski et al., 2012), como novo espaço de ação pública, faz parte da renovação do exercício democrático. Esse arranjo de governança local pode romper com as políticas tradicionais e combater com maior eficácia a pobreza e as desigualdades sociais, apoiando o desenvolvimento territorial. A descentralização administrativa e política valoriza o papel estratégico da esfera local na adaptação frente à globalização (Pecqueur, 2005). Embora seja frequentemente parte de uma rede de relações pré-existente, a governança local também pode promover a criação de novos "coletivos", empenhados na promoção de recursos específicos que identificam os agentes locais em questão (Billaud, 2014²).

Neste contexto, propomos, a seguir, os diferentes caminhos para atualizar uma planta de origem amazônica, o guaraná (Paullinia cupana Kunth var. sorbilis), cuja produção está associada principalmente ao território da cidadania do baixo Amazonas. Planta mítica para a etnia Sateré-Mawé - que a descobriu e iniciou o seu cultivo há cerca de mil anos -, o guaraná se espalhou ao longo dos séculos aos produtores rurais da região amazônica e do resto do Brasil (Lorenz, 1992). É cultivada pelas suas sementes estimulantes.

Oartigo apresenta um estudo em duas comunidades de agricultores familiares não indígenas, produtoras de guaraná, localizadas na região do médio Amazonas: a Associação dos Produtores do Rio Maués (APRORIM)33, do município de Maués, região de produção tradicional do guaraná, e a Cooperativa dos Produtores de Urucará (COOPAM), onde a planta foi introduzida. Estas organizações estão inseridas em cadeias alternativas de certificação socioambiental, em contraposição ao monopólio da multinacional American Beverage (AMBEV), que compra toneladas de guaraná no mercado regional. O objetivo do nosso estudo foi examinar o futuro dessas agriculturas familiares ${ }^{4}$ na região e sua capacidade de permanecer em um território onde estão

1 Os territórios da cidadania foram criados por meio de um programa de ação pública, em 2008, para promover o desenvolvimento das zonas rurais, identificadas como as mais pobres do país (IBGE, 2009).

2 BILLAUD, J.-P. L'utopie de la citoyenneté à l'épreuve d'un référentiel de politique publique, celui de la lutte contre la pauvreté et les inégalités. Paris, document de travail, 2014.

3 Os nomes da associação e da cooperativa foram alterados pelos autores.

4 A categoria "agricultura familiar", difundida no Brasil sobretudo a partir da implantação do Programa Nacional de Fortalecimento da Agricultura Familiar (PRONAF), refere-se à constituição de um setor de agricultores não patronais e não latifundiários, que exercitam formas próprias de viver e trabalhar, e, mesmo sob condições de produção restritas, estaria mais integrado às cidades e aos mercados (Wanderley, 2014).

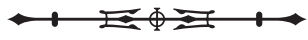


localizadas uma poderosa multinacional e uma organização de pesquisa pública reconhecida.

A pesquisa, realizada em 2011, analisou as transformações dos sistemas de gestão e de manejo do guaraná e as percepções sobre o cultivo da planta frente às tentativas de modernização das práticas e à chegada dos conceitos de desenvolvimento sustentável. Consideramos essas transformações como inovações territoriais ${ }^{5}$ que se apoiam em ações cujo objetivo é uma gestão local da produção e comercialização do guaraná. Busca-se entender quais são as formas de atividades individuais e coletivas favoráveis a esse processo. Prestou-se atenção especial às consequências das transformações ocorridas sobre a gestão da diversidade genética do guaraná. As observações sobre as práticas de renovação dos pés de guaraná foram confrontadas às estratégias coletivas de apropriação da planta ${ }^{6}$, mediante a adoção de dispositivos de valorização de práticas sustentáveis, tais como a certificação biológica, o comércio justo e a indicação geográfica.

Após apresentar a metodologia do trabalho de campo e o contexto de criação das duas organizações de produtores pesquisadas, estudou-se o universo político e econômico dos atores da produção de guaraná. Em seguida, foram detalhadas as cadeias alternativas de produção das duas organizações, para, finalmente, confrontar-se as práticas individuais e coletivas com os desafios da agricultura familiar no Brasil. A localização dos municípios estudados é apresentada na Figura 1.

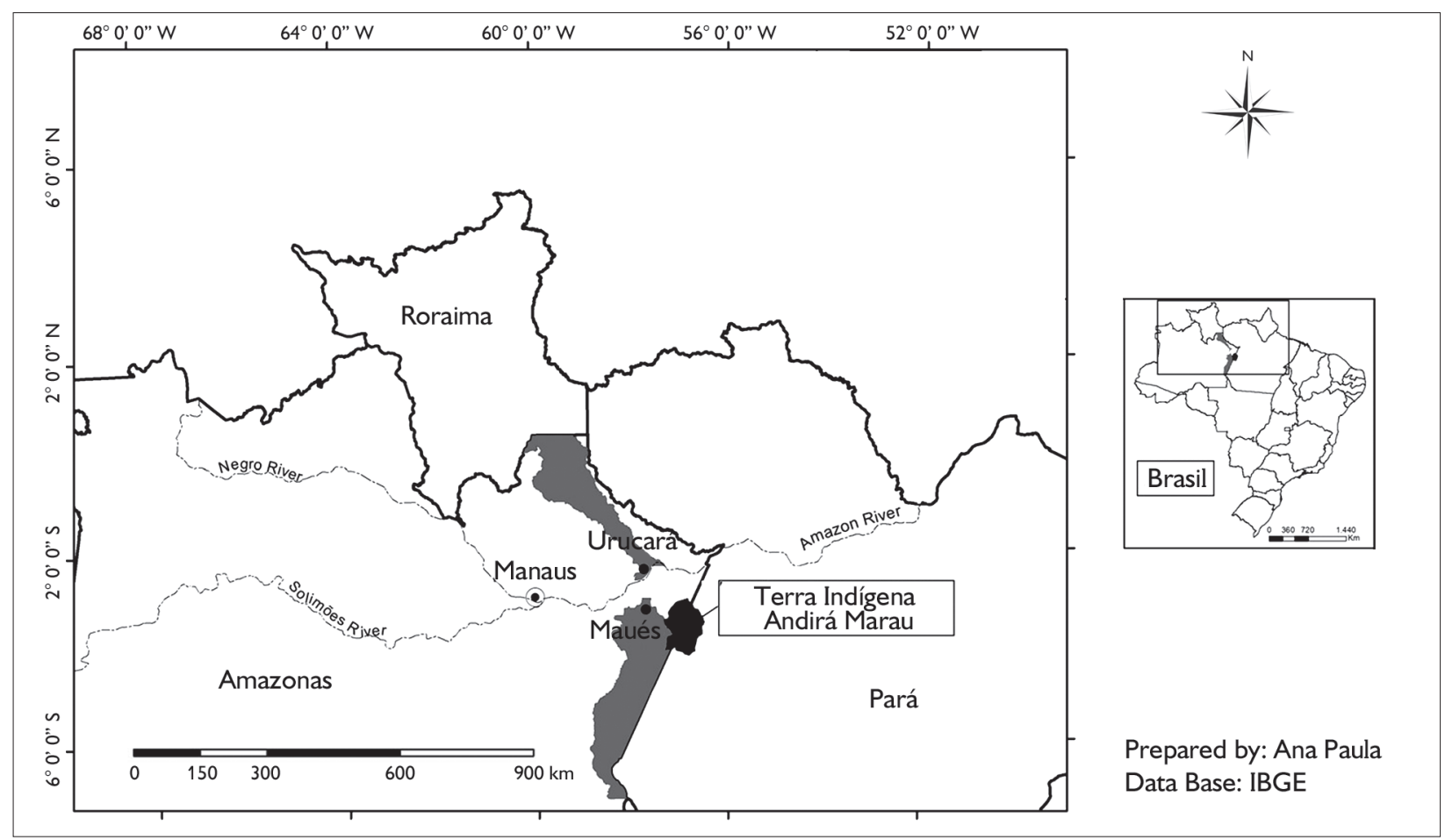

Figura 1. Localização da área de estudo (adaptado de Filoche e Pinton, 2014).

5 Vinculada a uma intencionalidade de mudança, a inovação remete ao processo de emergência do que é novo e a seu reconhecimento no meio de um grupo social (Fontan, 2004).

6 Com o advento da Convenção sobre a Diversidade Biológica (CDB), as práticas agroecológicas e os conhecimentos tradicionais associados são valorizados pelos seus papéis na conservação dos recursos genéticos, no entanto, cabe aos Estados assegurarem instrumentos adequados para a proteção desses patrimônios (Aubertin et al., 2007).

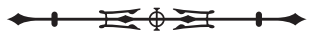




\section{METODOLOGIA}

A pesquisa está pautada em abordagens quantitativas, qualitativas e comparativas sobre os processos de qualificação do guaraná, segundo diferentes níveis de percepção: o do produtor, o da organização de produtores (OP), assim como o das instituições que gravitam em torno dessas organizações. $\bigcirc$ objetivo principal foi destacar, em reuniões, seminários e durante as estadas nas comunidades, as características territoriais relacionadas ao cultivo do guaraná, bem como a diversidade de práticas e representações dos atores. Por isso, foi escolhida a escala local para se compreender os sistemas agrícolas e as formas de valorização e apropriação do guaraná7. Entrevistas semiestruturadas e observações participativas foram utilizadas como técnica de investigação, por permitirem o acompanhamento, de modo mais próximo, do cotidiano dos agricultores e de suas famílias e possibilitarem uma inserção mais densa nas práticas e representações vivenciadas pelos agricultores (Correia, 2009). Considerando-se os sistemas produtivos como construções sociais e biológicas, realizou-se a pesquisa a partir da sociologia rural e da agronomia. $\bigcirc$ enfoque aproxima-se também da etnobotânica (Diegues, 2014), porém não foi o propósito da análise e da discussão dos resultados ${ }^{8}$.

A APRORIM é uma associação criada em 1994 para captar recursos do Fundo Constitucional de Financiamento do Norte (FNO), enquanto a COOPAM, como cooperativa, é o resultado de um processo demorado de maturação. Além dessas diferenças organizacionais (Tabela 1), ligadas às histórias e estratégias diferentes, as duas estão inseridas em cadeias alternativas de produção de guaraná através de processos de certificações socioambientais (produção orgânica e comércio solidário).

Em um primeiro momento, em março de 2011, a proposta do estudo foi apresentada às organizações em Urucará e Maués, a fim de se obter a anuência das lideranças. Em seguida, foram realizadas as entrevistas e visitas aos plantios, durante um primeiro período em Maués e em um segundo em Urucará. A pesquisa totalizou trinta e uma entrevistas e visitas em vinte guaranazais, em três comunidades de Maués e seis comunidades de Urucará.

Tabela 1. Características das organizações de produtores estudadas. Legendas: ${ }^{1}=$ certificadoras; IBD $=$ Instituto Biodinâmico; EcoCert Brasil $=$ vinculada à EcoCert France.

\begin{tabular}{|c|c|c|}
\hline & $\begin{array}{c}\text { Maués } \\
\text { Associação dos Produtores do Rio Maués }\end{array}$ & $\begin{array}{c}\text { Urucará } \\
\text { Cooperativa dos Produtores de Urucará }\end{array}$ \\
\hline Estatuto & Associação & Cooperativa \\
\hline Ano de criação & 1994 & 2001 \\
\hline Número de sócios em 2011 & 210 & 50 \\
\hline Número de entrevistados & 17 & 13 \\
\hline \multicolumn{3}{|c|}{ Mecanismos de valorização da produção } \\
\hline Certificação biológica & IBD'; em 2008; não renovada & EcoCert'; desde 2007 \\
\hline Comércio justo e solidário & - & EcoCert; não renovada \\
\hline
\end{tabular}

7 Os resultados juntam-se às conclusões dos programas franco-brasileiros PACTA 3 - "Populações, agrobiodiversidade e conhecimentos tradicionais associados" e BIOTEK - "Novas formas de socialização dos recursos biológicos, biotecnologia e gestão participativa da biodiversidade".

8 A pesquisa foi objeto de uma dissertação de mestrado, o qual foi realizado no Museu Nacional de História Natural, em Paris, em colaboração com AgroParisTech (Master "Environnement, Développement, Territoires et Sociétés", Paris, France) e o Centro de Ciências do Ambiente da Universidade Federal do Amazonas (CCA/UFAM).

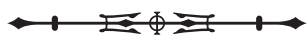


Utilizaremos o termo agricultores familiares para designar os produtores de guaraná de Maués e Urucará e para diferenciá-los dos agricultores indígenas representados neste estudo de caso pelos Sateré-Mawé. Os agricultores entrevistados foram indicados pelos seus representantes com o objetivo de se ter uma representatividade dos seguintes critérios: produção anual de guaraná ou abandono do plantio; idade do produtor; grau de importância do guaraná no sistema de produção (área de cultivo, acesso a créditos e renda); inscrição em processo de certificação; ano de ingresso na organização de produtores e grau de participação na organização. $\bigcirc$ roteiro das entrevistas tratou da história de vida do entrevistado (em especial, a origem dos conhecimentos relativos à gestão da planta), do sistema de produção e de cultivo (destacando-se o modo de renovação/restauração/substituição dos pés de guaraná), das formas de beneficiamento e comercialização, da relação com a OP e da assistência técnica. Salientaramse, nas falas dos produtores, as referências socioculturais, ecológicas e institucionais usadas no manejo e relativas à percepção da planta. Para a entrevista com as lideranças das $\mathrm{OP}$, focalizou-se no funcionamento da organização, nas estratégias e nas redes internas e externas.

As pesquisas de campo começaram em maio de 2011. Além das entrevistas com os produtores, buscaramse informações sobre a atuação das organizações governamentais e empresariais que têm um papel importante nas cadeias de produção do guaraná: a Secretaria de Produção Rural do Amazonas (SEPROR), o Instituto de Desenvolvimento Agropecuário e Florestal Sustentável do Amazonas (IDAM), o Serviço Brasileiro de Apoio às Micro e Pequenas Empresas (SEBRAE), a Empresa Brasileira de Pesquisa Agropecuária (EMBRAPA), a empresa American Beverage (AMBEV), a Fundação Centro de Análise, Pesquisa e Inovação Tecnológica (FUCAPI) e o Banco da Amazônia (BASA). A última viagem para campo aconteceu em dezembro de 2011, para apresentar e discutir os resultados com os representantes das duas organizações de produtores, os entrevistados e outros integrantes das organizações.

\section{GÊNESE DE DUAS ORGANIZAÇÕES DE PRODUTORES: ENTRE A HERANÇA DO 'CONHECIMENTO TRADICIONAL ASSOCIADO' E OS MODELOS DE MODERNIZAÇÃO DA AGRICULTURA}

A comunidade do rio Maués ${ }^{9}$ localiza-se, de barco, a vinte minutos da cidade de Maués. Quinze famílias moram no núcleo da comunidade, dividindo um espaço comum que se organiza no entorno da igreja, do centro social e da escola. A comunidade conta também com outras famílias que vivem em terras mais ou menos afastadas do centro, acessíveis a pé ou por meio de barco. À imagem do município, as produções de guaraná e de mandioca são os elementos principais do sistema de cultivo dos agricultores da comunidade. Os entrevistados reconhecem nos SateréMawé a origem do guaraná que eles plantam e consomem, o que aponta, de certa forma, para a origem indígena do seu conhecimento. Assim, eles formaram durante muitos anos os seus plantios de guaraná apenas com mudas nativas coletadas na floresta, à imagem dos Sateré-Mawé e, por isso, foram também chamados de 'produtores extrativistas'. Além de produzir guaraná, os agricultores de rio Maués costumam consumi-lo diariamente e usá-lo em várias preparações medicinais. As práticas de produção são transmitidas no núcleo familiar e comunitário: "é a nossa origem, aprendemos pequenos", conta um produtor. Por outro lado, a mitologia Sateré-Mawé ${ }^{10}$ parece pouco conhecida nas comunidades, onde é apenas popularizada através da Festa do Guaraná. Organizada pela prefeitura e patrocinada pela empresa Antártica desde 1979, a festa atrai a cada ano numerosos turistas para a cidade de Maués.

O nome da comunidade foi alterado pelos autores.

10 A planta representa a origem do conhecimento e tem um lugar central na cosmogonia Sateré-Mawé (Lorenz, 1992; Figueroa, 1997).

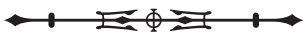


A história do município de Maués é ritmada por repetidos conflitos fundiários entre grandes patrões, comunidades caboclas e indígenas. Os patrões, além de apossarem-se de grandes extensões de terras, dominaram inicialmente o comércio de produtos extrativistas (principalmente da seringueira - Hevea sp. - e do paurosa - Aniba rosaeodora Ducke) e passaram, a seguir, a controlar o comércio do guaraná, mantendo, assim, seu poder econômico e político no município (Aubertin, 1996; Emperaire e Pinton, 1999). É somente através da ação do sindicato dos trabalhadores rurais que os caboclos ${ }^{11}$ conseguiram fazer valer os seus direitos nas décadas de $80 \mathrm{e}$ 90. Em paralelo, querendo impulsionar o desenvolvimento da agricultura familiar no município, a prefeitura, a SEPROR e os serviços de Assistência Técnica e Extensão Rural (ATER) incentivaram a criação de associações de produtores, para se beneficiarem do apoio financeiro do FNO, pilar dos pacotes tecnológicos. AAPRORIM surge, então, em 1994, entre as treze organizações criadas nessa data, tendo no cargo de presidente uma liderança que já tinha o papel de mediador entre as autoridades e a comunidade. Ela agrega rapidamente pessoas das outras comunidades interessadas em receber créditos. Em 2011, a APRORIM contava com 210 sócios, divididos entre a comunidade do rio Maués e 24 outras comunidades da região.

Os primeiros colonos que se instalaram em Urucará no início do século $X X$ viviam na várzea. As terras firmes da região ainda estavam pouco colonizadas, porém bastante exploradas para extração de madeira e de produtos, como a borracha, o óleo de copaíba, a castanha etc. (Carneiro Filho, 1996). Dependentes dos patrões, os ribeirinhos viviam da caça, da agricultura de várzea e do extrativismo, trocando os produtos florestais não madeireiros por mercadorias. A partir dos anos 30, a maioria as comunidades da região do médio Amazonas passou a cultivar a juta (Corchorus capsularis L.), cuja fibra era usada na fabricação de sacarias para armazenamento de produtos agrícolas, notadamente, do café (Pantoja, 2005). Após a introdução da fibra sintética e da consequente queda do mercado da juta, as famílias que dependiam dessa atividade voltaram a viver somente das atividades agroextrativistas.

Frente às difíceis condições de vida na várzea, missionários vindos da Itália trabalharam junto aos ribeirinhos na criação de comunidades de base ${ }^{12}$ em terra firme. Entre 1970 e 1980, 37 colônias agrícolas foram criadas a partir dessas comunidades em terras devolutas. Construídas em círculo a partir de um núcleo onde ficam as casas, a igreja e a escola, as colônias são planejadas em uma divisão igualitária da terra, seguindo um modelo de essência coletiva. A obtenção dos títulos de propriedade das terras aconteceu no início dos anos 80, pouco tempo depois da demarcação, através de uma "reforma agrária pacífica", como mencionado pelas lideranças.

Querendo priorizar a formação agrícola das famílias, os voluntários, a igreja, as autoridades locais e os novos agricultores juntaram-se e criaram, em 1972, o Centro de Treinamento Rural de Urucará (CETRU), no qual os técnicos são os próprios missionários. Quatro anos depois foi criado o Núcleo de Treinamento Intensivo (NTI), que ofereceu um ensino técnico agrícola para os jovens, além de ser uma escola de ensino fundamental. Os técnicos do CETRU trouxeram as primeiras sementes de guaraná de Maués em Urucará, em 1973, cientes do potencial de valorização da planta. Após a criação de mudas no viveiro da instituição, alguns produtores interessados plantaram um a dois hectares em seus lotes, orientados pelos técnicos que foram em Maués e fazendo as suas próprias experimentações.

11 - termo 'caboclos' refere-se aos descendentes mestiços de índios e colonos europeus, porém as suas características ultrapassam essa mera origem (Grenand e Grenand, 1990) e agregam dimensões sociogeográficas. Eles são considerados aqui como 'pequenos produtores', suscetíveis de se juntarem aos agricultores familiares (ver Wanderley, 2003).

12 As comunidades eclesiais de base são ligadas à Igreja Católica que, incentivadas pela Teologia da Libertação, se espalharam principalmente nos anos 1970 e 1980 no Brasil, durante a ditadura militar (Burdick, 1996).

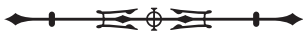


Segundo os entrevistados, naquela época, os agricultores "não estudavam", mas sabiam "trabalhar com a terra" e é a partir desses conhecimentos locais, complementados pelos conhecimentos dos técnicos do CETRU e da Empresa de Assistência Técnica e Extensão Rural do Estado do Amazonas (EMATER) ${ }^{13}$, que se fortaleceram as práticas locais de produção do guaraná. Nesse sentindo, o NTI foi fundamental. Formando mais de 2000 alunos, a instituição trouxe um ensino técnico sobre agricultura, pecuária e artesanato para os jovens, com o intuito de combater o êxodo rural. Incentivados a colocar na prática os aprendizados nos plantios da família, confrontações aparecem entre os filhos e os pais, que, por exemplo, 'dificilmente acreditavam' no efeito benéfico da poda do guaranazeiro. A geração que passou pelo NTI teve um novo olhar sobre as práticas dos pais: "desde que eu era pequeno, vi meu pai trabalhar somente daquele jeito e não funcionava. Roçamos tantas vezes, fizemos tantas roças com o nosso pai. (...) Quero trabalhar do meu jeito".

Apesar do sucesso dos plantios de guaraná, os produtores tornaram-se dependentes do monopólio da AMBEV, que ditava o preço do mercado, o que não favorecia a agregação de valor ao produto. Os voluntários italianos, "como portadores de um projeto pedagógico de libertação da população do jugo dos agentes da circulação mercantil" (Neves, 2009), incentivaram a organização dos produtores para libertá-los dos atravessadores e da AMBEV. Associando-se a uma cooperativa já existente em Urucará, eles conseguiram criar uma marca e vender uma safra para um comprador da Itália em 1996, nas modalidades do comércio sustentável. Porém, devido às divergências de opiniões entre os cooperados, o projeto foi descontinuado. Dois anos mais tarde, em 1998, o CETRU e o NTI pararam de funcionar junto com os projetos governamentais, que, até essa data, apoiavam financeiramente as duas iniciativas. Conflitos políticos impediram de salvar as instituições e até hoje parecem bloquear qualquer tentativa de ensino técnico agrícola. Apesar da saída dos missionários e do fim dos centros de ensino, as comunidades ainda permanecem com os valores de organização social e de libertação trazidos pelos missionários. A criação de uma cooperativa em 2001 apareceu como a continuação lógica do caminho percorrido pelos produtores desde os anos setenta.

Graças a uma viagem pela Itália, em 1999, os futuros fundadores da COOPAM familiarizaram-se com o cooperativismo e passaram a conhecer as oportunidades criadas pelas certificações socioambientais nos mercados europeus. Apoiados pela Organização das Cooperativas do Brasil (OCB), alguns agricultores, verdadeiras lideranças, mobilizam 29 parceiros e criaram a Cooperativa dos Produtores de Urucará. Instalada no antigo CETRU, na periferia da cidade de Urucará, a cooperativa contava, em 2011, com 50 cooperados e trabalhava com mais de 100 produtores, tendo como missão a valorização do guaraná.

\section{A DIFUSÃO DE VARIEDADES MELHORADAS COMO FERRAMENTA DE MODERNIZAÇÃO DOS SISTEMAS AGRÍCOLAS TRADICIONAIS}

O processo de modernização da produção de guaraná iniciou-se em 1921, com a criação de um refrigerante, o 'Guaraná Antártica'. A rápida difusão do consumo da bebida em escala nacional incentivou a proprietária da marca a se instalar em Maués nos anos quarenta, onde ela comprou, em 1971, uma fazenda de mil hectares, iniciando um projeto de melhoramento da produção de guaraná, em parceria com um segundo ator econômico importante, a EMBRAPA. O objetivo da Antártica era distribuir variedades melhoradas aos produtores da região, para poder comprar grandes quantidades de frutos a baixo custo (Pinton, 2010).

Em paralelo à criação de duas unidades de pesquisa da EMBRAPA no Amazonas, sendo uma em Maués dedicada à pesquisa experimental em condições de campo,

13 A EMATER foi criada em 1977 como agência oficial de Assistência Técnica e Extensão Rural. Após uma série de mudanças, ela se tornou, em 2007, o Instituto de Desenvolvimento Agropecuário e Florestal Sustentável (IDAM) (IDAM, s.d.). 
a empresa de pesquisa pôde dedicar-se ao seu intuito de modernização da produção, pela criação e difusão de cultivares ${ }^{14}$ de guaraná com o lançamento do seu programa de "melhoramento genético do guaranazeiro", em 1976. A partir de um material coletado desde os anos 50 na região de Maués, variedades foram sendo desenvolvidas por reprodução sexuada e, a partir dos anos oitenta, multiplicadas por reprodução vegetativa, técnica também chamada de estaquia ou clonagem (Atroch et al. , 2009) ${ }^{15}$. Desde 1998, a EMBRAPA criou e disponibilizou 19 cultivares $^{16}$. Os critérios de seleção referem-se à produtividade (em termos de quantidade e estabilidade ao longo do tempo) e à resistência às principais doenças ${ }^{17}$, com o objetivo de aumentar a produção por hectare e, consequentemente, diminuir a taxa de desmatamento. A produtividade nas comunidades é considerada baixa pelos agrônomos e técnicos, em decorrência da não renovação dos pés de mais de 25 anos, do uso de material não selecionado, da densidade insuficiente dos plantios, da ausência de podas e dos problemas fitossanitários.

Para incentivar a adoção dessas tecnologias pelos produtores que não podiam comprar as mudas, foram criados programas de créditos específicos pelos bancos, associados à adoção de práticas de cultivo prescritas em 'pacotes tecnológicos'. Eles visavam à implantação do plantio de guaraná consorciado com a mandioca nos dois primeiros anos. $\bigcirc$ produtor receberia diretamente as variedades melhoradas dos viveiros credenciados pela EMBRAPA, os insumos químicos das lojas agropecuárias e a assistência técnica através da SEPROR e do IDAM. Para as diferentes etapas do cultivo, parcelas eram liberadas diretamente para o produtor, e um técnico fazia a vistoria do seu trabalho. Após quatro anos de plantio, o produtor começaria a reembolsar o banco. Para obtenção do empréstimo, o produtor precisaria realizar um projeto de vida e um projeto técnico, ter anuência do sindicato dos trabalhadores rurais, estar cadastrado em uma estrutura associativa etc.

$\bigcirc$ trabalho de pesquisa da EMBRAPA contribuiu também par o desenvolvimento da cutura fora da região. Assim, a desterritorialização da produção do guaraná, iniciada no começo do século XX (Monteiro, 1965), acelerou-se: com o aperfeiçoamento da produção em monocultivos, os estados do Acre, Rondônia, Mato Grosso e Bahia passaram a abastecer, com abundância, os mercados nacionais e internacionais ${ }^{18}$. Hoje, a EMBRAPA alega possuir o maior banco genético de guaraná e as 'provas cientificas' da sua qualidade de melhorista (programa de melhoramento, protocolos, publicações etc.), necessárias para proteger os direitos do melhorista mediante registro desses cultivares no Registro Nacional de Cultivares ${ }^{19}$.

${ }_{14}$ Um cultivar é uma variedade selecionada e melhorada que seja claramente distinguível de outros cultivares conhecidos e que seja homogêneo e estável através de gerações sucessivas.

15 A expressão fenotípica dos caracteres do guaraná varia muito entre a matriz e as plantas descendentes por reprodução sexuada. Em consequência, os pés oriundos das sementes de clones não necessariamente herdam das características que foram fixadas nos clones.

16 A EMBRAPA registrou os 19 cultivares no Registro Nacional de Cultivares, necessário para a produção, o beneficiamento e a comercialização de sementes e mudas. Para proteger o cultivar e obter direitos de propriedade, é preciso registrá-lo no Serviço Nacional de Proteção de Cultivares, o que a EMBRAPA fez com seis destes, entre 2011 e 2012.

17 As doenças são a antracnose e o superbrotamento, cujos vetores são os fungos Colletotrichum guaranicola e Fusarium decemcellulare. O guaraná sofre também ataques do inseto Liothrips adisi.

18 Em 2001, 24 clones da EMBRAPA foram introduzidos na região da Mata Atlântica na Bahia e permitiram ao estado tornar-se o maior produtor de guaraná do país. Segundo os dados do IBGE (s.d.), a Bahia foi responsável por 58\% da produção nacional em 2009, e 73\% em 2011.

19 Para proteger os resultados das pesquisas agronômicas, o governo brasileiro aderiu, a partir de 1999, ao sistema da União Internacional para a Proteção de Cultivares (UPOV), após ter aprovado a lei federal de proteção de cultivares, que foi complementada, em 2002, pela lei de semestes e mudas e pela criação do Registro Nacional de Cultivares (RNC), onde todas as novas variedades devem ser inscritas para poderem ser legalmente comercializadas (Filoche e Pinton, 2014; Santilli, 2009). As cultivares obtidas em estações de pesquisa são de propriedade de seus obtentores.

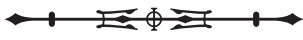


Desde a sua implementação na região, a estratégia da Antártica foi levar variedades melhoradas e orientação técnica para os produtores em troca da compra da totalidade da sua safra. Até os anos 1990, a empresa focou na melhoria de sua linha de produção. Sua atividade dupla (produção e industrialização da matéria-prima) permitiu a ela o controle da cadeia produtiva, fazendo com que se tornasse o principal comprador de guaraná produzido localmente. Tal poderoso ator econômico no território de Maués influenciou fortemente os políticos locais, que pretendiam divulgar a região de Maués, terra natal da planta, como a capital mundial do guaraná. Um evento anual, chamado de 'o dia do guaraná', cujo principal financiador era a empresa, foi organizado. Os produtores eram convidados a visitar a fazenda da empresa e seus 400 hectares de plantios, apresentados como um modelo de sistema de cultivo. Apesar de chegar a distribuir 60 mil mudas por ano, a lógica extensionista top down utilizada pela empresa não teve uma boa aceitação por parte dos agricultores. A compra da Antártica em 1998 pela multinacional American Beverage e o programa de desenvolvimento do governo do estado do Amazonas "Zona Franca Verde"20, destinado a estimular o desenvolvimento rural com base na valorização de seus recursos naturais, surgiram como oportunidades para mudanças nas estratégias de difusão da tecnologia de modernização da produção do guaraná. AAMBEV pretendia ser reconhecida em nível internacional como uma empresa socialmente e ambientalmente responsável. No contrato que a multinacional assinou com o estado do Amazonas, em 2003, a empresa compromete-se a investir 61 milhões de reais em projetos sociais e agrícolas no município de Maués. Em 2008, foi criado o 'programa de excelência do guaraná', o qual recompensa com material agrícola os produtores que obtiveram a melhor safra, lembrando as feiras agrícolas controladas pela elite rural.
Configurando-se durante muito tempo como o maior produtor de guaraná do Brasil, o município de Maués vê sua produção minguar e os investimentos destinados a intensificar a produção local fracassarem. Na visão dos atores dominantes, esse fracasso se deve principalmente à incapacidade dos agricultores familiares de adotarem as inovações tecnológicas que lhes foram propostas e de tornarem seus sistemas de produção uma agricultura familiar dinâmica.

As ações de pesquisa e extensão rural procuram a modernização das formas de produção que devem passar pela adoção da inovação tecnológica, seguindo modelos de inovação descendente e que ignoram tanto as práticas locais como o papel das organizações locais sobre a atitude do agricultor (Darré, 1999). Pode-se supor que o modelo de introdução da inovação tecnológica não convenceu os agricultores, pouco familiarizados com as modificações propostas pelos pacotes tecnológicos modernizantes e, sobretudo, negligenciados no próprio processo de inovação, pois são considerados como simples usuários passivos da tecnologia. Com o intuito de convencê-los, a EMBRAPA criou os 'dias de campo', estratégia similar à da AMBEV, onde são realizadas visitas às unidades demonstrativas, que são plantios-modelo implementados nas áreas de alguns agricultores, como experimentos pilotos em escala. Por outro lado, a instituição de pesquisa analisa os impactos do uso dos clones e elabora o sistema de avaliação dos impactos ambientais da inovação tecnológica (por meio da empresa Ambitec), baseada em enquetes socioeconômicas e ambientais junto aos produtores.

A difusão das variedades melhoradas, como quadro de referência para a modernização, enfrentou recentemente mudanças de paradigmas (requalificação dos saberes locais, reconhecimento do seu papel na conservação, renovação da diversidade agrícola e a

\footnotetext{
20 Denominação do programa do governo do estado do Amazonas (2003-2007), que propunha a interiorização do desenvolvimento econômico com base na exploração econômica de base agroflorestal para equilibrar o modelo concentrador e urbano ao modelo da Zona Franca de Manaus (Araújo e Paula, 2009).
}

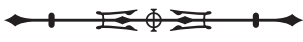


territorialização da ação pública) que impulsionaram os atores da pesquisa agronômica e da assistência técnica a adaptarem suas estratégias à realidade dos agricultores. Estas novas estruturas conceituais também promovem a difusão de sistemas de recuperação dos recursos locais e de práticas sustentáveis. A decentralização das políticas públicas relacionadas com a promoção do 'desenvolvimento territorial sustentável' estimulou o surgimento de novos atores interessados no guaraná, que vão desafiar a abordagem modernizadora em favor das tentativas de reterritorialização da produção. Essas iniciativas coincidem com o lançamento, pelo governo federal, do programa 'Territórios da Cidadania', incluindo o território do baixo Amazonas (Caniello et al., 2013), que engloba todos os municípios produtores de guaraná e terra indígena dos Sateré-Mawé21 (Figura 2).
A valorização do guaraná é percebida como uma ferramenta de desenvolvimento potencial para este 'território'. Neste contexto, e com o financiamento do programa, são desenvolvidos projetos de Indicações Geográficas (IG) 22 pelo SEBRAE e pela FUCAPI para o guaraná de Maués.

Os agricultores têm que adequar suas práticas de manejo do ambiente e da produção a novos mecanismos que visam à preservação do meio ambiente e à valorização das suas práticas e saberes, apropriando-se ou não das ferramentas e aproveitando as oportunidades. Eles se tornam potencialmente atores coletivos da mudança. Os reflexos locais desse fenômeno na produção do guaraná em Maués e Urucará se fez sentir a partir das mudanças nas práticas de cultivo e de valorização do saber local adotadas pela COOPAM e pela APRORIM.

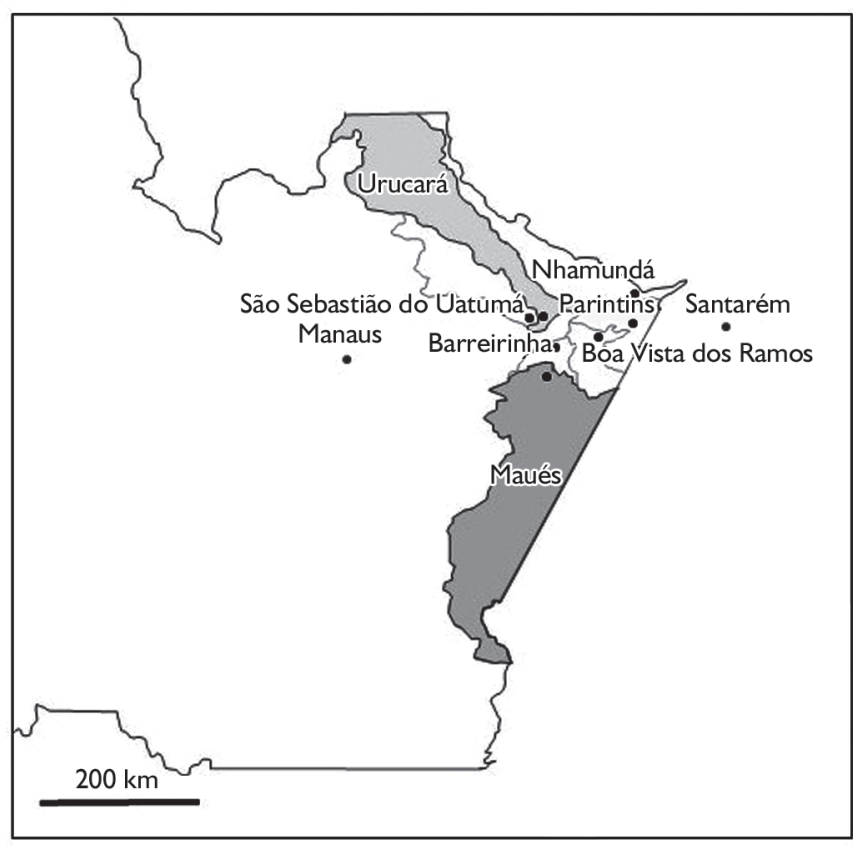

Estado do Amazonas

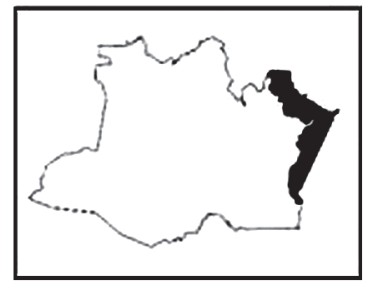

Figura 2. Os municípios do território da cidadania do baixo Amazonas (adaptado de PTDRS, 2011, p. 17).

\footnotetext{
21 Não serão abordados neste artigo os projetos referentes aos Sateré-Mawé, que serão objeto de próximas publicações.

22 Adotados pelo Brasil em 2004, as IG existem sob duas formas - indicação de procedência (IP) e denominação de origem (DO). Menos restritiva, a IP garante uma origem geográfica controlada do produto e permite proteger o uso do nome da localidade. A atribuição das IG são feitas sob o controle do Instituo Nacional de Propriedade Industrial (INPI).
}

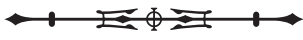




\section{O PROCESSO DE CONSTRUÇÃO DAS CADEIAS DE PRODUÇÃO ALTERNATIVAS NA 'TERRA DO GUARANÁ' EM MAUÉS E A EMANCIPAÇÃO DOS PRODUTORES DE URUCARÁ}

Logo após a sua criação, em 1994, a APRORIM serviu de canal para solicitação de créditos voltados ao plantio consorciado de guaraná com mandioca. No entanto, os pacotes tecnológicos apoiavam-se em estruturas incapazes de assegurar o seu bom funcionamento frente à diversidade social e geográfica do município. Os serviços de ATER (SEPROR e IDAM) sofrem da falta de recursos técnicos e humanos, que não permite atender as $180^{23}$ comunidades espalhadas no município. A lógica top down da extensão rural, que se traduz pela exclusão do agricultor do processo de inovação, fez com que poucos produtores se apropriassem das variedades melhoradas e dos itinerários técnicos associados. Na comunidade do rio Maués, houve tentativas sem sucesso de estadia do técnico. Dificuldades na gestão das associações, conflitos e manipulações políticas tornaram o quadro complexo e contribuíram para a crise deste processo de mudança. Em consequência, observou-se o endividamento da maioria dos agricultores que conseguiram créditos em 1994 e 2004. Em 2011, cerca de 70\% dos produtores do município de Maués endividados eram inadimplentes, segundo o Banco da Amazônia (comunicação pessoal de um representante do BASA).

A intervenção de novos atores veio a redinamizar a cadeia de produção no município, com a introdução dos princípios da agricultura biológica, em expansão no Brasil. A intervenção também reflete a emergência de formas privadas de iniciativas que concorrem com as das instituições públicas (Mutersbaugh, 2005; Bartley, 2007), embora essas últimas sempre procurem regular as primeiras. A agricultura biológica é definida como um sistema de produção com baixo impacto ecológico, excluindo os fertilizantes, produtos químicos solúveis e os agrotóxicos. Em 2007, o Brasil apresentou um crescimento das áreas certificadas entre 50 e 60\% ao ano e uma área total de 6 milhões de hectares (Apex, Brasil, 2007)24. No entanto, a agricultura orgânica continua subdesenvolvida na Amazônia: as condições para o seu exercício são mais complexas do que em outros lugares (falta de capacitação e organização dos produtores, falta de infraestruturas etc.) e as condições de comercialização são difíceis (Blanc e Kledal, 2012).

Em 2002, no quadro do programa do governo do Amazonas de apoio às exportações, a FUCAPI organizou, pela primeira vez, formações voltadas aos agricultores (seminários e cursos) sobre agroecologia, apicultura e processos de certificação socioambiental. $\bigcirc$ projeto não fugia dos objetivos de modernização da produção, porém considerou aparentemente as especificidades locais. Nesse sentido, vale ressaltar a criação pela FUCAPI de despolpadora e descascadora adaptadas aos produtores para reforçar a sua independência frente às agroindústrias. O SEBRAE também realizou oficinas de higiene e de boas práticas de fabricação. $O$ objetivo era ajustar o produto às exigências dos mercados internacionais, em específico, os europeus e japoneses.

A APRORIM foi um canal para realização de cursos e formações que foram bem recebidos pelos produtores e permitiram a certificação de alguns deles. Em 2003, vendeu seu guaraná para a Europa no comércio solidário. Cinco anos depois, em 2008, quinze produtores da APRORIM e de outra associação local receberam a certificação orgânica da certificadora IMO Brasil. Após dois anos de certificação orgânica exitosa do guaraná, não houve renovação do processo por falta de caixa, devido à má gestão financeira da associação. Além disso, ocorreu certa estagnação da associação pela difícil renovação da diretoria.

23 Levantamento do IDAM, de 2011.

24 Prova da importância desse tema, foi publicado, em outubro de 2012, o decreto n 7.794, que instituiu a "política nacional de agroecologia e produção orgânica".

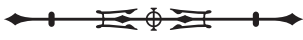


A própria história de criação da associação, que não surgiu da mobilização coletiva, traz elementos essenciais à compreensão da sua situação atual. Os empréstimos individuais conduziram a responsabilidades e dívidas coletivas: a APRORIM não pode receber financiamentos enquanto os seus membros estão endividados. Além disso, a liberação das parcelas do empréstimo só acontece quando é comprovado que todos os produtores plantaram as mudas recebidas no 'pacote'. Criam-se tensões e bloqueios para a continuidade dos projetos da associação (por exemplo, a certificação), além de uma forte descrença nas estruturas associativas. As autoridades explicam este fracasso pela suposta resistência dos agricultores à inovação, caracterizando as suas práticas como 'tradicionais'. No entanto, nossa pesquisa constatou transformações significativas nas técnicas de plantios e na relação com a planta, devido à interação entre produtores e os técnicos extensionistas dos serviços locais ou de fora da região, tais como os da EMBRAPA, AMBEV, SEPROR, FUCAPI, SEBRAE e mesmo da Deutsche Gesellschaft für Internationale Zusammenarbeit (GTZ) ${ }^{25}$. Os entrevistados descrevem práticas experimentadas e adotadas, como o aumento da densidade de plantio (de 100 pés por hectare para 400), novas técnicas de assombreamento da muda, adoção da cobertura vegetal do solo etc. Como explica um produtor: "cada técnica que aparece, a gente aprende uma coisa”. Algumas técnicas são recusadas ou dificilmente aplicadas, como a renovação dos pés de guaraná de mais de 40 anos e as podas, que, segundo alguns entrevistados, "tiram a força do guaraná". No caso dos insumos químicos, numerosos produtores explicam que não foram adotados por causa dos fracassos observados com o mau uso dos produtos: "ninguém aprendeu bem como fazer o adubo". Mais tarde, a nova orientação técnica baseada na agroecologia fortaleceu essas práticas: "essa coisa de química eu nunca aceitei, sempre fui contra".
A APRORIM, através da qual foram organizados cursos e formações, não foi citada como referência nos discursos dos entrevistados, pois não socializou técnicas ou conceitos, fontes de inovações. Foi ressaltado o caso de uma liderança, já falecida, que 'encorajava' os produtores a trocar conhecimento para criar a inovação, realizando demonstrações de diferentes itinerários técnicos no seu plantio, proporcionando a aprendizagem e a experimentação. Não foi citada outra iniciativa parecida onde há trocas de informações e experimentações sobre técnicas de produção. A má reputação dos serviços de ATER e a ausência de um projeto coletivo freiam a participação e inscrição dos produtores em tais iniciativas, enquanto a falta de uma organização social estruturada torna o processo mais lento e difícil. Da mesma forma, a integração da maioria de produtores nas dinâmicas do desenvolvimento sustentável foi comprometida.

O projeto de Indicação Geográfica (IG) para o guaraná de Maués que surgiu em 2008 desafia também a capacidade dos agricultores de se organizarem para a requalificação dos seus saberes sobre a gestão da planta e do território. O primeiro projeto desse tipo para a região norte trata-se de um projeto político da prefeitura, que visa também destacar o produto e os seus derivados nos 'nichos de mercados'. Por trás do selo, o município de Maués, que é o maior produtor do estado ${ }^{26}$, deseja assentar a sua reputação de terra de tradição do guaraná, e impedir o uso abusivo do seu nome nos mercados. O projeto de IG, que se beneficia de parcerias com o SEBRAE, a FUCAPI e o Ministério da Agricultura, Pecuária e Abastecimento (MAPA), além dos órgãos de ATER, visa a indicação de procedência, que valoriza as características do produto estreitamente ligadas à sua origem geográfica ${ }^{27}$. Após os seminários de sensibilização dos produtores feitos em 2008, houve, em 2011, a redação e a validação do protocolo de

${ }^{25}$ GTZ, atual GIZ, agência de cooperação técnica internacional alemã.

${ }^{26}$ Com 54,9\% da produção do estado do Amazonas (IBGE, 2009).

27 Os Sateré-Mawé, envolvidos no registro de uma denominação de origem (que salienta a originalidade dos fatores naturais e culturais no caráter específico do produto), recusaram a inscrição da Terra Indígena Andirá-Marau no projeto de Indicação Geográfica da região.

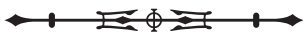


produção do guaraná junto às famílias escolhidas para participar do lançamento da IG. Na ausência de uma cooperativa robusta para receber a indicação e controlar a aplicação do protocolo, foi criado um consórcio, que reúne uma cooperativa e seis associações, dentro das quais a APRORIM. Porém, o Instituto Nacional da Propriedade Industrial responsável por esse processo que aplica direitos coletivos de propriedade intelectual sobre o produto não aprovou a liberação do selo, que deveria envolver mais de 500 guaranacultores.

A partir do que foi observado na APRORIM, pode-se duvidar da adesão de um número tão grande de famílias ao projeto de Indicação Geográfica. Além de pertencer a um território, é necessário identificar-se com uma forma comum de produção e beneficiamento do guaraná. Como essa partilha pode acontecer no contexto de Maués, onde a lógica descendente dos projetos demostrou as suas falhas até hoje? Através do projeto de Indicação Geográfica, o SEPROR pretende 'colocar o poder na mão do produtor', porém essa intenção precisa ser traduzida por atividades de formação e acompanhamento, para proporcionar a apropriação pelos atores locais do projeto e dos direitos que ele desperta. Em princípio, a IG permitiria aos agricultores a independência do monopólio da AMBEV. Apesar dessas tentativas de agregação de valor e da existência da associação, em 2010 e 2011 os produtores da APRORIM venderam sua produção principalmente para essa empresa e para os atravessadores ${ }^{28}$.

A cooperativa se posicionou desde o começo favoravelmente à promoção da agroecologia, apoiada em sua tradição de gestão democrática e participativa e antecipando as oportunidades de valorização que a transição agroecológica poderia trazer em termos de valorização e competitividade da produção. A cooperariva exportou o seu produto para Europa desde a sua criação, mas apenas em 2003 foi criada a marca 'Guaraná Urucará', querendo, assim, valorizar e proteger o seu produto. $\bigcirc$ guaraná dos cooperados ainda precisa transitar por Manaus para ser moído, porém, em 2011, a COOPAM vislumbrou o projeto de criação de uma pequena agroindústria.

Graças ao apoio da FUCAPI e do SEBRAE, que intervieram neste município assim como em Maués, e de um comprador francês, os produtores obtiveram a certificação orgânica e de comércio justo da EcoCert em 2007. Com o ingresso de um dos fundadores da cooperativa no IDAM, a instituição aderiu ao projeto da COOPAM e juntas combinaram os esforços para melhorar os sistemas de produção de base agroecológica. Como explica um ator-chave da cooperativa: "é preciso muita conversa para obter resultados e a mudança tem que surgir da experiência dos produtores". Faz-se necessário repensar os modos de intervenção e adequar a prática do agricultor às teorias do técnico. No IDAM de Urucará, as concepções do desenvolvimento agrícola evoluem progressivamente e se transformam com a promoção dentro da instituição de um modelo de assistência técnica que valoriza a participação e o voluntariado. Com o apoio da FUCAPI, os sócios da cooperativa defendem um projeto pedagógico acerca da certificação orgânica e trabalham durante três anos para convencer os produtores e as instituições locais. Eles podem ser considerados como pioneiros pelo fato de defenderem pelo fato de defender um caminho ainda não promovido pelos ministérios brasileiros. Nesse sentindo, a cooperativa conseguiu negociar com o Banco do Brasil a exclusão dos insumos químicos dos pacotes tecnológicos, ou seja, assegurou para os produtores o acesso ao crédito e às variedades melhoradas, conservando as práticas locais de produção adicionadas às inovações agroecológicas. O IDAM e a COOPAM desenvolveram suas próprias técnicas de melhoramento de variedades, com a criação de um viveiro a partir de clones cedidos pela EMBRAPA. As atividades de mutirões continuam sendo incentivadas,

${ }^{28}$ O projeto de IG de Maués seria reelaborado em 2012 pelo SEBRAE Amazonas, em parceria com o Ministério da Agricultura e com o apoio da prefeitura municipal.

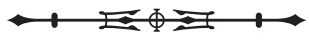


apesar de não constar no itinerário técnico no qual estão baseados os créditos. Hoje, a cooperativa possibilita a 70 produtores exportarem o guaraná com a certificação orgânica. A certificação 'comércio justo' foi cancelada em 2010 pelos altos custos anuais de renovação. A AMBEV, assim como a Coca-Cola, baseada em Manaus, ainda são importantes compradores para a cooperativa, que continua trabalhando em paralelo com produto não certificado. Em 2009 e 2010, eles foram os principais compradores, devido à crise financeira mundial que reduziu drasticamente as exportações da cooperativa.

A COOPAM é portadora de um projeto de emancipação econômica e tecnológica dos agricultores, apoiando-se na ação coletiva. Apesar dos cooperados já terem sidos sensibilizados a esses conceitos pela sua própria história social, esses valores foram se enfraquecendo com o fim dos centros de ensino técnico e a absorção crescente dos valores capitalistas, que "atrofiaram as formas coletivas de organização do trabalho" (Fraxe et al., 2007). A mudança provocada pela cooperativa transparece nos discursos dos entrevistados: "[a cooperativa] abriu os olhos de muita gente", "[antes] era cada um por si", "trabalhar em sociedade é muito bom (...), depois a gente tem mais conhecimentos". Fundada por uma liderança forte, a cooperativa socializa as informações e incentiva os agricultores a se tornarem parceiros e a agregarem mais produtores nessa caminhada. A COOPAM traz uma orientação técnica própria e visa manter a parceria com o IDAM. Segundo um entrevistado: "a cooperativa ajuda sempre. A gente busca eles, eles verificam, dão uma olhada”. Além da agregação de valor, busca-se conscientizar os produtores sobre questões de proteção do meio ambiente e cooperativismo, entre outros, para eles aderirem aos projetos de certificação socioambiental.

Assim, existe incentivo ao uso do consórcio do guaraná com leguminosas, bem como o uso de biofertilizantes e de alternativas ao uso do fogo. A cooperativa quer capacitar o produtor sobre a gestão da propriedade rural, seguindo o modelo do empreendedor rural (contabilidade, planejamento das produções etc.). Ela participa da divulgação das inovações, tanto tecnológicas como sociais, e da sensibilização das famílias sobre as problemáticas globais. Certa consciência da importância da ação coletiva aparece na fala de um produtor: "basta não seguir a regra e todo mundo é prejudicado". Vista como uma organização pioneira no Brasil, a COOPAM assenta-se em um grupo de líderes e em uma rede de parceiros locais (OCB, IDAM, SEBRAE) e internacionais (compradores na Europa) que aderiram ao seu projeto.

Diferenças nítidas foram observadas nos processos de estruturação das cadeias entre a APRORIM e a COOPAM, apesar de haver numerosos participantes em comum. As cadeias se distinguem, sobretudo em relação aos seus tempos de reação e atuação frente às mudanças e oportunidades que surgem, o que também foi observado quando se trata das práticas de gestão da planta, como será discutido a seguir.

\section{PLANTAS NATIVAS, VARIEDADES MELHORADAS E CLONES: A HETEROGENEIDADE DAS PRÁTICAS DE RENOVAÇÃO DOS PÉS DE GUARANÁ}

O guaranacultor faz o manejo da diversidade do guaraná por meio das suas práticas de obtenção e renovação das plantas que cultiva. As entrevistas efetuadas nos dois municípios evidenciaram informações importantes sobre essas práticas e nos esclarecem sobre as percepções e representações associadas. Vale ressaltar que nas duas regiões estudadas as expressões 'guaraná melhorado', 'variedade' e 'cultivar' não foram usadas pelos agricultores na sua grande maioria. Nos seus discursos, os entrevistados falam de 'tipos' ou 'qualidades' diferentes de guaraná, segundo a origem desta planta.

Nas comunidades estudadas, a agricultura fundamenta-se nas práticas de derrubada e queima para a formação de roças de 1 a 2 ha. $\bigcirc$ guaraná é geralmente consorciado com a mandioca e, em alguns 
casos, foi observado que a espécie é inserida em sistemas agroflorestais complexos. Algumas semanas após o início da época da chuva e do plantio da mandioca, são plantadas as mudas de guaraná, sem trabalho do solo além da abertura das covas. A questão do tempo de produtividade é relativa: para os técnicos e agrônomos, o pé precisa ser renovado após 25 anos de produção. Na visão dos agricultores, não existe regra, alguns pés serão produtivos além dos 40 anos, outros não, isso faz parte do 'mistério' do guaraná.

Para formar um plantio de guaraná, o agricultor pode usar suas mudas criadas a partir de sementes ou com a técnica da alporquia ${ }^{29}$. Ele pode usar mudas doadas ou trocadas com outro agricultor (em geral, trata-se de um agricultor que faz parte da família, o qual autoriza a coleta de mudas nas suas terras, troca ou doa mudas caseiras ou de viveiro). A busca de mudas espontâneas em áreas de floresta ou em antigas roças também faz parte das estratégias sinalizadas. Os produtores diferenciam dois 'tipos' de 'guaraná nativo' oriundos da floresta: o 'guaraná verdadeiro' (Paullinia cupana Kunth var. sorbilis), variedade coletada para ser cultivada, e o 'falso-guaraná' (guaranárãn ${ }^{30}$, Paullinia cupana Kunth var. cupana), descrito como a variedade selvagem, que não está selecionada como matriz, mas é observada em Maués e Urucará. Finalmente, o agricultor pode recorrer a um recurso ex situ, comprando as mudas de um viveiro. A Tabela 2 sintetiza as técnicas observadas em cada município.

\section{A BUSCA DO 'FILHO DO MATO'}

O sistema de cultivo do guaraná dos agricultores de Maués baseia-se na busca do guaraná nativo na floresta, prática que seria herdada dos Sateré-Mawé. Os plantios de guaraná do povo Sateré-Mawé são formados dos pés nativos, coletados na floresta a partir da seleção de 'plantas mães', que eles deixam crescer e frutificar. As mudas que germinam naturalmente dessas matrizes são extraídas e transferidas em seguida na área do plantio (Henman, 1982). O único processo de seleção do guaraná existente seria a escolha, que acontece na floresta, das boas 'plantas mães' e das melhores mudas a extrair. Exceto um entrevistado, todos os agricultores encontrados em Maués dizem usar essa técnica, onde o guaraná é designado como 'filho', 'filhote do mato' ou, ainda, chamado de 'nativo', 'da natureza', 'original'. Além de procurar mudas de guaraná na floresta, os entrevistados relataram como prática comum a coleta de mudas em antigos plantios, bem como em roças produtivas (mudas formadas por sementes caídas durante a colheita). A facilidade da coleta em plantio produtivo ou abandonado permite a renovação rápida de pés mortos ou improdutivos. Em todos os casos, preferência é dada a uma muda 'viçosa, bonita', cujas folhas estão 'bem verdes e bem bonitas', além de ter uma raiz sólida.

Em Urucará, a busca do 'filho do guaraná' não se refere ao guaraná nativo, mas às mudas espontâneas dos plantios abandonados. Essa prática é citada nas entrevistas como comum para renovar pontualmente os

Tabela 2. Diversidade de origens do guaraná nos plantios dos entrevistados.

\begin{tabular}{c|c|c|c|c}
\hline & $\begin{array}{c}\text { Clone } \\
\text { (viveiro) }\end{array}$ & $\begin{array}{c}\text { Guaraná de } \\
\text { semente (viveiro) }\end{array}$ & $\begin{array}{c}\text { Guaraná de } \\
\text { semente (caseiro) }\end{array}$ & $\begin{array}{c}\text { Guaraná nativo } \\
\text { coletado }\end{array}$ \\
\hline Maués (12 investigados) & 8 (2 do viveiro da AMBEV) & 8 & 4 & 11 \\
\hline Urucará (17 investigados) & 16 & 17 & 10 & - \\
\hline
\end{tabular}

\footnotetext{
${ }^{29}$ Vale ressaltar que a técnica da alporquia não é comum entre os agricultores e resulta da observação do fenômeno natural de reprodução vegetativa de pés de guaraná na floresta. Um agricultor explica que "essas mudas de galos que crescem no mato" são comuns, mas não tão resistentes quanto as de sementes. Para a clonagem, os viveiristas usam hormônios de enraizamento e controlam as condições edafoclimáticas durante o crescimento da muda.

30 Ou guaraná-rana. O sufixo rãn ou rana significa "parecido" na língua Tupi (Cunha, 1999).
} 
pés improdutivos ou até para criar uma roça inteira, já que necessita apenas da autorização do dono da roça, e não de investimento financeiro. Não se fala de guaraná 'nativo' ou 'da natureza', pois é reconhecido pelos entrevistados que o guaraná nativo não existe em Urucará, mas sim em Maués. Como explica esse agricultor, em Urucará, a prática seria comum e se refere a uma quantidade importante de mudas:

O pessoal tira muito para plantar. (...) O dono [da roça] leva o pessoal. Por isso que eu não corto ele [o antigo guaranazal].

- Rapaz tem filho de guaraná no teu guaranazal?

- Tem! vai lá buscar.

E aí leva. 300, 400... é pra plantar...numa bacia de plástico assim, dá pra caber 400, leva até 500.

Apesar dos pacotes tecnológicos, os guaranacultores conservam suas práticas de coleta de mudas, mesmo que elas sejam nativas ou oriundas da reprodução natural entre roças produtivas e abandonadas, mobilizando e preservando, assim, uma diversidade de saberes, que vão desde os critérios pessoais de seleção até técnicas de plantio de mudas e manejo do território.

\section{SELECIONAR E FAZER GERMINAR AS SUAS SEMENTES}

Antes da divulgação da técnica de clonagem, as instituiç̧̃es de extensão rural ensinavam técnicas de seleção e reprodução sexuada e incentivavam a construção de viveiros comunitários para criação de mudas a partir de sementes. Em Urucará, a aprendizagem das técnicas de seleção e reprodução dos melhores pés e a criação de mudas se deu através dos viveiros do CETRU e das comunidades. As primeiras sementes são oriundas de Maués ('guaraná da marca boa', segundo um produtor de Urucará). Os produtores, que até então plantavam as sementes diretamente na roça 'no cabo do terçado', desenvolveram estratégias próprias de seleção de sementes, como a diferenciação de pés fêmeas e machos (teoria ainda mencionada, porém não validada pelos técnicos do IDAM). Todos os guaranacultores de Urucará entrevistados possuem plantios de dez a trinta anos formados por esses 'pés duros' ou pés de sementes. Mais da metade dos entrevistados continua selecionando e plantando as suas sementes, experimentando também com sementes de pés clonados.

Na comunidade do rio Maués, a seleção e o plantio de semente para formar as roças de guaraná foram mencionados pelos entrevistados como uma prática comumente empregada pelos antigos e hoje ainda aplicada pontualmente. Como diz este agricultor:

Os antigos plantavam assim. Eles tiravam da árvore - guaraná, escolheram aqueles guaranás mais graúdos que tinha, botavam numa vasilha lá... iam no roçado deles, e com a ponta do terçado mesmo enterravam lá.

Apesar disso, o IDAM e a FUCAPI não conseguiram a adesão dos produtores ao projeto de viveiro implantado na comunidade. $O$ sucesso dos plantios financiados que incluem mudas de viveiros contrasta com esse tipo de prática, apenas mencionado pelos quatro produtores mais antigos.

\section{A DIFUSÃO CRESCENTE DOS CLONES}

A partir dos anos oitenta, os viveiros deixam de produzir e incentivar o uso de mudas oriundas de sementes e passam a usar a tecnologia da clonagem dos cultivares, que requer a adoção de hormônios de enraizamento e de um sistema de nebulização para controle da umidade do ambiente. Os cultivares clonados são apresentados pela EMBRAPA como uma tecnologia resistente à antracnose, principal praga que afeta o guaranazeiro, dez vezes mais produtiva que os pés de sementes e de desenvolvimento mais rápido, se cultivados com o itinerário técnico adequado que inclui podas regulares e insumos químicos (Atroch, 2001). Entre Maués e Urucará, diferenças evidentes foram observadas nas formas de apropriação e representação dos cultivares clonados pelos guaranacultores. 
Em Urucará, a cooperativa trabalha em parceria com o IDAM e com o viveiro local (propriedade do gerente do IDAM) no melhoramento dos cultivares. O viveiro trabalha com dez cultivares da EMBRAPA livres de uso ${ }^{31}$ e produz até cinquenta mil clones por ano, dependente do número de produtores que tem um projeto de plantio financiado ${ }^{32}$. Além de multiplicar as mudas, o viveiro busca produzir novos cultivares. Assim, quando os produtores observam um pé com características interessantes de produção, resistência às pragas etc., os técnicos são chamados para coletar galhos e identificar e reproduzir o pé destacado. O produtor, dono da matriz, recebe $10 \%$ das mudas criadas ou o pagamento equivalente. Pela participação do produtor no processo de criação da nova tecnologia ("a gente observa e eles vêm pegar"), cria-se uma relação de confiança entre o guaranacultor, o futuro clone e os técnicos.

Além desse método participativo de seleção de variedades, a cooperativa e os técnicos do IDAM e do viveiro desenvolveram um sistema de georreferenciamento das melhores matrizes encontradas, bem como um mapeamento detalhado dos plantios com identificação de cada pé (origem, estado), traduzindo, assim, uma real vontade de melhoramento das variedades locais. No que concerne ao produtor, apesar deste não se apropriar dos nomes dados aos cultivares pelos pesquisadores da EMBRAPA (Brasil Sementes (BRS) Maués, BRS Andirá etc.), ele reconhece as diferentes 'qualidades' de guaraná na sua roça pelas características fenotípicas. Com a negociação da cooperativa com o Banco do Brasil para liberar créditos adaptados aos plantios agroecológicos, ou seja, tirando os adubos químicos do pacote tecnológico ${ }^{33}$, um grande número de agricultores adotou os clones. Os entrevistados mostraram um real interesse a respeito dos clones, como se traduz na citação de um deles: "usar pé de sementes não é mais um bom negócio". Dezesseis dos 17 entrevistados mencionaram ter pelo menos um plantio de guaraná clonado. Apesar disso, oito entre eles mostraram interesse em conservar pés de sementes e em continuar suas práticas de seleção e germinação de sementes. A COOPAM combina as estratégias para melhorar os sistemas de produção dos cooperados. Através da cooperação com o IDAM, objetiva o desenvolvimento de clones de variedades adaptadas aos sistemas agroecológicos. Certificação orgânica e variedades melhoradas andam juntas.

Em Maués, oito dos 13 produtores entrevistados possuíam plantios de guaraná clonado. Apesar de o produtor experimentar os pés clonados e endividar-se com essa nova tecnologia, a pesquisa mostrou a desconfiança dele em relação aos clones e aos agentes defensores da inovação. Entre os produtores entrevistados, o clone é visto como uma tecnologia de laboratório, um 'objeto químico', que dependente de adubos e pesticidas desconhecidos. Por isso, destacou-se uma preferência para o pé de semente que tem mais 'força', 'vitaminas'. A tecnologia necessária à criação de clones faz com que os produtores que adotam essas variedades tornem-se dependentes dos técnicos e viveiros para renovar os seus plantios. Em Urucará, essa relação de dependência está sendo atenuada pela confiança e parceria que existem entre os guaranacultores, a cooperativa e os técnicos. Por outro lado, a associação de agricultores de Maués não desenvolve estratégias coletivas quanto às inovações tecnológicas.

Nas duas regiões estudadas, a grande maioria dos produtores entrevistados mantém certa diversidade nos plantios, criando combinações entre guaraná nativo, guaraná

31 Dez cultivares entre os que não foram inscritos no Serviço Nacional de Proteção de Cultivares (SNPC). Ver Filoche e Pinton (2014), a respeito dos direitos de propriedade sobre o guaraná.

${ }^{32}$ Em Urucará, o Banco do Brasil é responsável por este tipo de crédito. O financiamento, assim como em Maués, é apenas voltado ao uso de clones.

${ }^{33}$ Como sinalizado por EcoCert (comunicação pessoal da certificadora), a certificação orgânica não impede o uso de clones e deixa o produtor escolher a origem dos pés de guaraná.

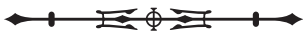


de semente selecionada e guaraná melhorado (de semente ou clonado). Essa escolha pode refletir as preocupações dos produtores em termos de produtividade e de resistência dos plantios às pragas e doenças. As práticas de diversificação representam, sobretudo, um manejo da agrobiodiversidade que vai de encontro à padronização das variedades, incentivada pelo modelo modernizante de produção.

\section{CONSIDERAÇÕES FINAIS}

A multiplicação das oportunidades de mercado, aliada ao sucesso comercial dos derivados do guaraná, representa fatores propícios à diversificação das formas de gestão da planta na sua região de origem, após muitos anos de imposição de um modelo produtivista. Esperava-se que, com a criação do território da cidadania do baixo Amazonas, houvesse a multiplicação de iniciativas voltadas para a inclusão social e o desenvolvimento territorial, e surgimento de novos territórios de ação. No entanto, como observado, o processo de criação de duas cadeias produtivas enfrentou e ainda enfrenta a hegemonia do modelo convencional de modernização do monopólio agroindustrial, que já estava instalado nos municípios estudados, e as ambições políticas do governo local de Maués, que reivindica seu estatuto de capital mundial do guaraná por meio de seu projeto de IG. Esse processo também é prejudicado pela dificuldade dos agentes governamentais, entre os quais os agentes de extensão rural, em se adaptarem às abordagens verdadeiramente participativas que valorizam os recursos territoriais. $\bigcirc$ frágil capital social dos agricultores locais os tornam ainda mais suscetíveis aos efeitos da dominação do capital monopolista. Nossas observações vão ao encontro às de Brondízio (2014), segundo o qual, os agentes de extensão rural na Amazônia brasileira têm dificuldades para levar em conta os saberes locais, além das práticas de manejo da planta serem pouco (re)conhecidas.

Como salientamos neste artigo, as entrevistas realizadas descrevem diferentes processos de inovação iniciados na região e que se transformam em reação às mudanças conceituais surgidas no âmbito das iniciativas privadas e governamentais de desenvolvimento rural. $\bigcirc$ papel dos processos de inovação na aceitação de novas tecnologias, assim como o papel da história social da constituição das organizações suscetíveis de adotá-las, é elemento fundamental na compreensão das práticas coletivas de manejo da planta e das escolhas individuais dos produtores.

A presença de lideranças locais em Urucará, verdadeiros empreendedores sociais voltados para o futuro, é um fator importante de distinção, pois facilitou a mediação entre produtores, líderes e agentes de extensão rural. Sua experiência de cooperativismo facilitou o processo de apropriação da planta 'melhorada', tanto na escala individual como coletiva. Em Maués, ao contrário, a associação ainda tem dificuldade em convencer os produtores de participar da construção conjunta de estratégias de valorização do guaraná e dos saberes e técnicas de produção. Os agricultores de Maués não detêm essa cultura política e não se beneficiam da presença contínua de uma liderança estruturante que os represente. Foram os atores sociais externos ao território que investiram seus meios para promover a participação desses agricultores em iniciativas de valorização do produto.

De modo paradoxal, a indicação geográfica para o município, como está apresentada pelas autoridades, visa a padronizar as práticas no seu território e não interrompe o seu projeto inicial de modernização do cultivo local da planta por difusão de variedades melhoradas. A lógica top down prevalece porque não há integração dos agricultores nas discussões. $\bigcirc$ projeto de IG não está fundamentado socialmente, mas apenas tecnicamente pelos seus promotores. No entanto, as práticas individuais que descrevemos revelam a capacidade de inovação e mudança dos agricultores, assim como o seu apego cultural pela planta. A construção participativa de um projeto democrático de IG poderia articular práticas e conhecimento tradicional, associados com a incorporação e adaptação de inovações, tomando-se em conta estas dinâmicas locais (Fournier, 2008). 
O desenvolvimento de sistemas de produção de bases agroecológicas no território da cidadania do baixo Amazonas é dificultado pela hegemonia do referencial de modernização agrícola, que orienta as estratégias dos agentes econômicos mais poderosos da cadeia de produção. A padronização das variedades, assim como das formas de manejo do guaraná, ameaça o futuro da agrobiodiversidade e a própria diversidade genética das plantas. As possibilidades de reterritorialização da planta remetem também às discussões sobre a apropriação do guaraná através de direitos de propriedade. A estratégia da COOPAM em relação ao melhoramento genético do guaraná traduz a vontade de seus membros de se emanciparem do monopólio da EMBRAPA. A cooperativa de Urucará busca identificar as variedades locais adaptadas aos sistemas de cultivos por eles defendidos, no intuito de valorizar um produto cuja qualidade poderia ser vinculada a bases territoriais culturalmente significantes. Para isso, ela antecipa e busca novos parceiros, a fim de melhorar a viabilidade dos sistemas de produção locais, conseguindo, assim, certa reputação, apesar de estar fora da 'terra do guaraná'. Os agricultores de Maués são menos cientes das consequências associadas aos direitos de propriedade, embora eles defendam intuitivamente práticas tradicionais de manejo do guaraná, em paralelo à introdução das variedades clonadas. Por outro lado, destacam-se os Sateré-Mawé, que se reivindicam como responsáveis pela diversidade genética da planta e defendem o seu território como o santuário cultural e ecológico do guaraná (Fraboni, 2001).

Finalmente, ressaltamos que a coexistência de diversas cadeias de produção (produtivistas e alternativas) na mesma região traz valores contraditórios: entre quem defende um produto de qualidade indiferenciada e de baixo custo (no nosso caso, a AMBEV) e quem valoriza a tipicidade e a diferença (seria o caso dos agricultores de Maués); entre quem acredita na superioridade da técnica e quem requalifica a tradição (no caso, a cooperativa); entre quem investe na agricultura convencional (AMBEV e EMBRAPA) e quem defende o princípio da conservação in situ/on farm da agrobiodiversidade (Maués e Urucará). O verdadeiro desafio para essas agriculturas é a sua capacidade em coabitar umas com as outras, para responder às diversas demandas dos 'consumidores', mas também para defender a multiplicidade dos sistemas agrícolas. Através dos 'mercados da biodiversidade', os produtores de guaraná do território do baixo Amazonas poderiam ganhar maior visibilidade no Brasil e no mundo, desde que eles sejam capazes de se organizar e definir seu próprio território de ação, para estruturarem e defenderem valores compartilhados.

\section{AGRADECIMENTOS}

Em primeiro lugar, aos guaranacultores e às suas organizações, que nos receberam e aceitaram participar da pesquisa. Igualmente, às equipes do IDAM, da SEPROR, da FUCAPI, da EMBRAPA e da AMBEV, pela colaboração neste trabalho. À AgroParisTech (UFR Sociologies), que financiou a pesquisa no quadro dos seus editais para projetos científicos, assim como à Universidade Federal do Amazonas e ao Programa de Pós-graduação em Ciências Ambientais e Sustentabilidade na Amazônia.

\section{REFERÊNCIAS}

AGENCIA BRASILEIRA DE PROMOÇAO DE EXPORTAÇÕES E INVESTIMENTO (APEX BRASIL). [s.d.]. Disponível em: <http:// www.apexbrasil.com.br/>. Acesso em: 15 Abr. 2013

ARAÚJO, J. J. C. N.; PAULA, E. A. Novas formas de desenvolvimento do Amazonas: uma leitura das ações do Programa Zona Franca Verde. Revista Brasileira de Gestão e Desenvolvimento Regional, v. 5, n. 3, p. 140-154, 2009.

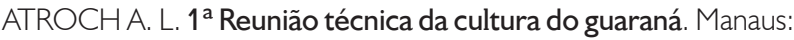
Embrapa Amazônia Ocidental, 2001. (Documentos, 16).

ATROCH, A. L.; NASCIMENTO FILHO, F. J.; ANGELO, P. C. S.; FREITAS, D. V.; SOUSA, N. R.; RESENDE, M. D. V.; CLEMENT, C. R. Domesticação e melhoramento de guaranazeiro. In: BOREM, A.; LOPES, M. T. G.; CLEMENT, C. R. (Eds.). Domesticação e melhoramento: espécies amazônicas. Viçosa: UFV, 2009. p. 333-361.

AUBERTIN, C. Heurs et malheurs des ressources naturelles en Amazonie brésilienne. Cahier des Sciences Humaines, v. 32, n. 1, p. 29-50, 1996. 
AUBERTIN, C; PINTON, F; BOISVERT, V. Les marchés de la biodiversité. Paris: IRD Edition, 2007.

BARTLEY, T. Institutional emergence in an era of globalization: the rise of transnational private regulation of labor and environmental conditions. American Journal of Sociology, v. 113, n. 2, p. $297-$ 351, 2007.

BLANC, J.; KLEDAL, P. R. The Brazilian organic food sector: prospects and constraints of facilitating the inclusion of smallholders. Journal of Rural Studies, v. 28, n. 1, p. 142-154, 2012.

BOISVERT,V.; CARON, A. Valorisation économique des ressources et nouveaux marchés. In: AUBERTIN, C.; PINTON, F.; BOISVERT, V. (Eds.). Les marchés de la biodiversité. Paris: IRD Edition, 2007. p. 195-217.

BRONDÍZIO, E. S. Agriculture intensification, economic identity, and shared invisibility in Amazonian peasantry: caboclos and colonists in comparative perspective. Culture, Agriculture, Food and Environment, v. 26, n. 1-2, p. 1-24, 2004.

BURDICK, J. Procurando Deus no Brasil. Petrópolis: Vozes, 1996.

CANIELLO, M.; PIRAUX, M.; BASTOS, V. V. S. Identidade e participação social na gestão do programa Territórios da Cidadania: um estudo comparativo. Estudos de Sociologia e Agricultura, Rio de Janeiro, v. 21, n. 1, p. 84-107, 2013.

CARNEIRO FILHO, A. Les principaux produits extractivistes et leurs zones de production. In: EMPERAIRE, L. (Dir.). La forêt en jeu: l'extractivisme en Amazonie centrale. Paris: ORSTOM; UNESCO; Latitudes 23, 1996. p. 85-91.

CERDAN, C.; VITROLLES, D. Valorisation des produits d'origine: contribution pour penser le développement durable dans la Pampa Gaúcha au Brésil. Géocarrefour, Lyon, v. 83, n. 3, p. 191-200, 2008.

CERDAN, C.; SAUTIER D. Construction territoriale de la qualité des produits de l'élevage dans le Nordeste brésilien. In: COLLOQUE INTERNATIONAL SUR LES SYSTEMES AGROALIMENTAIRES LOCALISES, 1., 2002, Montpellier. Anais... Montpellier: CIRADTERA, 2003. p. 1-15.

CONVENTION ON BIOLOGICAL DIVERSITY. [s.l.]: Nações Unidas/UNEP, 1992,. Disponível em: <https://www.cbd.int/ convention/text/>. Acesso em: 4 abr. 2011.

CORREIA, M. C. B. A observação participante enquanto técnica de investigação. Pensar Enfermagem, v. 13, n. 2, p. 30-36, 2009.

CUNHA, A. G. Dicionário histórico das palavras portuguesas de origem Tupi. Brasília: Editora UnB, 1999.

DARRÉ, J.-P. La production de connaissance pour l'action. Arguments contre le racisme de l'intelligence. Paris: Éditions de la MSH/INRA, 1999.
DIEGUES, A.-C. The role of ethnoscience in the build-up of ethnoconservation as a new approach to nature conservation in the tropics. Revue d’Ethnoécologie, v. 6, p. P. 1-14, 2014.

EMPERAIRE, L.; PINTON, F. Gestion de la diversité variétale du manioc dans le moyen Amazone: Maués (Amazonas - Brésil). Relatório de pesquisa. Brasília: BRG/CNPq/ISA/IRD, 1999.

FIGUEROA, A. L. G. Guerriers de l'écriture et commerçants du monde enchanté: histoire, identité et traitement du mal chez les Sateré-Mawé (Amazonie Centrale, Brésil). 1997. Tese (Doutorado em Antropologia) - Ecole des Hautes Etudes en Sciences Sociale, Paris, 1997.

FILOCHE, G.; PINTON, F. Who owns guaraná? Legal strategies, development policies and agricultural practices in Brazilian Amazonia. Journal of Agrarian Change, v. 14, n. 3, p. 380-399, 2014.

FONTAN, J. M.; KLEIN J.-L.; TREMBLAY, D. G. Innovation et société: pour élargir l'analyse des effets territoriaux de l'innovation. Géographie, Économie, Société, v. 6, n. 2, p. 115-128, 2004.

FOURNIER, S. Les indications géographiques: une voie de pérennisation des processus d'action collective au sein des systèmes agroalimentaires localisés? Cahiers d'Agricultures, v. 17, n.2, p. 547-551, 2008.

FRABONI, M. The waraná project. In: HUBER, Simon (Ed.). Fighting poverty: social innovations and new coalitions, Global Dialogue at Expo 2000. Eschborn: GTZ Office Expo, 2001. p. 124-129.

FRAXE, T. J. P.; WITKOSKY, C. A.; PEREIRA, H. S. (Orgs.). Comunidades ribeirinhas amazônicas: memória, ethos e identidade. Manaus: Editora da Universidade do Amazonas, 2007.

GRENAND, P.; GRENAND, F. L'identité insaisissable: les Caboclos amazoniens. Etudes Rurales, v. 120, n. 1, p. 17-39, 1990.

HENMAN, A. R. Guaraná (Paullinia cupana var. sorbilis): ecological and social perspectives on an economic plant of the central Amazon basin. Journal of Ethnopharmacology, São Paulo, v. 6, n. 3, p. 311-338, 1982.

INSTITUTO BRASILEIRO DE GEOGRAFIA E ESTATÍSTICA (IBGE). Banco de dados agregados. [s.l.]: IBGE, [s.d.]. Disponível em: <http://www.sidra.ibge.gov.br/>. Acesso em: 12 out. 2011.

INSTITUTO BRASILEIRO DE GEOGRAFIA E ESTATÍSTICA(IBGE). Estados@-Amazonas. [s.l.]: IBGE, 2009. Disponível em: <www. ibge.gov.br/estadosat/temas. php? sigla=am\&tema=lavouraperman ente2009 > . Acesso em: 2 abr. 2011.

INSTITUTO DE DESENVOLVIMENTO AGROPECUÁRIO E FLORESTAL SUSTENTÁVEL DO ESTADO DO AMAZONAS (IDAM). Nossa história. [s.d.]. Disponível em: <http://www.idam. am.gov.br/o-idam/quem-somos/> . Acesso em: 21 abr. 2011

LORENZ, S. Sateré-Mawé: os filhos do guaraná. São Paulo: Centro de Trabalho Indigenista, 1992. 
MONTEIRO, M. Y. Antropogeografia do guaraná. Manaus: INPA, 1965. (Cadernos da Amazônia, 6).

MUTERSBAUGH, T. Just-in-space: certified rural products, labor of quality, and regulatory spaces. Journal of Rural Studies, v. 21, n. 4, p. 389-402, 2005.

NEVES, D. P. Os ribeirinhos-agricultores de várzea: formas de enquadramento institucional. Novos Cadernos NAEA, v. 12, n. 1, p. 67-92, 2009.

NIEDERLE, P. A. (Org.). Indicações greográficas: qualidade e origem nos mercados alimentares. Porto Alegre: Editora da UFRGS, 2013.

PANTOJA, M. C. A várzea do médio Amazonas e a sustentabilidade de um modo de vida. In: LIMA, Deborah (Org.). Diversidade socioambiental nas várzeas dos rios Amazonas e Solimões: perspectivas para o desenvolvimento da sustentabilidade. Manaus: Ministério do Meio Ambiente, Instituto Brasileiro do Meio Ambiente e dos Recursos Naturais Renováveis, 2005. p. 157-206.

PECQUEUR, B. Le développement territorial: une nouvelle approche des processus de développement pour les pays du Sud. In: ANTHEAUME, B.; GIRAUT, F. (Eds.). Le territoire est mort. Vives les territoires. Paris: Ed. IRD, 2005. p. 295-316.

PINTON, F. La valorisation du guaraná en Amazonie Brésilienne: culture de rente et/ou culture des filières? In: INNOVATION AND SUSTAINABLE DEVELOPMENT IN AGRICULTURE AND FOOD, 2010, Montpellier. Anais... Montpellier: EPSO, 2010. p. 1-8. Disponível em: <https:/hal.archives-ouvertes.fr/hal-00525455/ document>. Acesso em: 10 ago. 2011.
PLANO TERRITORIAL DE DESENVOLVIMENTO RURAL SUSTENTÁVEL DO BAIXO AMAZONAS (PTDRS). Território Baixo Amazonas, Caritas Arquidiocesana de Manaus. Estudo Técnico. Manaus: SDT, MDA, 2011.

SANTILLI, Juliana. Agrobiodiversidade e direitos dos agricultores. São Paulo: Peirópolis, 2009.

WANDERLEY, M. N. B. O campesinato brasileiro: uma história de resistência. Revista de Economia e Sociologia Rural, Piracicaba, v. 52, supl. 1, p. 25-44, 2014.

WANDERLEY, M. N. B. Agricultura familiar e campesinato: rupturas e continuidades. Estudos Sociedade e Agricultura, Rio de Janeiro, n. 21, p. 42-61, 2003.

WITKOSKI, A. C.; MIGUEZ, S. F.; SOUZA, D. S. R.; PEREIRA, H. S.; FRAXE, T. P. The Brazilian Federal Government Policy of rural territories: two cases in the Amazonas state. In: ASHLEY A. P.; CROWTHER, D. (Orgs.). Territories of social responsibility: opening the research and Policy. 1. ed. Surrey: Gower, 2012. v. 1, p. 133-148.

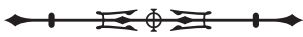


